\title{
Neurological and neuropsychological performance in HIV seropositive men without symptoms
}

\author{
R H McAllister, M V Herns, M J G Harrison, S P Newman, S Connolly, C J Fowler, \\ M Fell, P Durrance, H Manji, B E Kendall, A R Valentine, I V D Weller, M Adler
}

University College and Middlesex School of Medicine, Middlesex Hospital, Mortimer Street, London W1N 8AA

Department of Neurology

R H McAllister

M J G Harrison

H Manji

Department of Neuropsychology

M V Herns

S P Newman

$M$ Fell

$P$ Durrance

Department of Neurophysiology

$S$ Connolly

C J Fowler

Department of

Neuroradiology

B E Kendall

Department of

Genitourinary

Medicine

I V D Weller

$M$ Adler

Radiology

Department, Royal

Free Hospital, Pond

Street, London NW3

A R Valentine

Correspondence to:

Professor Harrison

Received 4 March 1991 and in revised form 5 June 1991. Accepted 14 June 1991

\begin{abstract}
Ninety five HIV seropositive and 32 seronegative homosexual men were recruited to a prospective study of the early features and natural history of the neurological manifestations of HIV infection. There was no evidence from the initial neurological examination, a neuropsychological test battery, nerve conduction studies, somatosensory evoked potentials from the legs, P300 event related auditory evoked potentials, magnetic stimulation of the motor cortex, or MRI scans that HIV infected men without symptoms in CDC groups II/III differed significantly from a well matched seronegative comparison group. Only the subgroup in CDC IV showed evidence of impairment, and this was restricted to their performance on some of the cognitive tests. The results imply that, despite early invasion of the CNS by HIV, major disturbances of function manifest themselves only when the patient becomes immunosuppressed. The importance of an appropriate comparison group and awareness of the potentially confounding influences such as age, education, exposure to alcohol and drugs, and mood and anxiety in such studies is stressed. The essentially negative findings are important in the understanding of the pathogenesis of neurological effect in HIV infection and in the design and interpretation of therapeutic trials.
\end{abstract}

There is evidence that the nervous system is affected by HIV, early in the course of infection. Meningitis, encephalitis, myelitis, and an inflammatory type of peripheral neuropathy have all been described at the time of seroconversion, ${ }^{1}$ and cerebrospinal fluid (CSF) studies show evidence of persistent infection with cellular and IgG responses in a large proportion of asymptomatic HIV seropositive subjects. $^{2}$ Despite this, most infected individuals remain neurologically asymptomatic until clinical immunosuppression develops. ${ }^{3}$ In a few cases (5-10\%) the event which signals the development of symptomatic immunosuppression is the appearance of clinically significant cognitive impairment for which no opportunistic or other cause can be found. A degree of cognitive impairment is thought eventually to affect 30 to $40 \%$ of those with AIDS, ${ }^{4}$ though pathological studies show an even higher prevalence of a subacute encephalitis, ${ }^{5}$ which is believed to be due to HIV itself. $^{6}$ Five to $10 \%$ of subjects also develop signs of damage to the peripheral nervous system, ${ }^{7}$ and at postmortem as many as $25 \%$ show signs of spinal cord disease. ${ }^{8}$ Controversy exists over the possibility that asymptomatic seropositive individuals might show subclinical evidence of evolving damage to either the central or peripheral nervous system. In particular it has been suggested that such individuals show impaired performance when subjected to a battery of neuropsychological tests. ${ }^{9}$ At the end of 1987 we therefore embarked upon a longitudinal study of a cohort of seropositive and seronegative homosexual men, who underwent neurological, neurophysiological, and neuropsychological tests at six to nine month intervals. Annual recording of event related evoked potentials (P300s), central motor conduction times with magnetic stimulation, and magnetic resonance imaging of the brain (MRI scanning) were added to the assessments at the second visit. This report of the cross sectional comparison of seropositive and seronegative subjects combines the clinical, neuropsychological, and neurophysiological data from the first visit and the MRI, magnetic stimulation, and P300 data collected for the first time at the second visit.

\section{Subjects and methods}

The study population was recruited after a full discussion of the protocol from the MRC funded cohort being followed in the academic department of genitourinary medicine. The original cohort consisted of 172 seropositive and 70 seronegative subjects. Ninety five seropositive and 32 seronegative men agreed to take part in the neurological research programme. None had been diagnosed as having any neurological manifestation of HIV infection and none were receiving antiviral therapy when recruited, but 15 had group IV HIV disease according to the Centers for Disease Control (CDC) classification. $^{10}$ Of these, five had Kaposi sarcoma, two recent pneumocystis pneumonia, and eight constitutional symptoms or oral candida, or both. All recruited subjects were homosexual or bisexual, and in most seropositive subjects seroconversion was estimated as having occurred between 1983-84 on the basis of a series of point prevalence studies in the clinic 
population. ${ }^{11}$ The seronegative comparison group came from partners or other homosexuals attending the department who were then, and as late as 1989 were still seronegative for HIV-1. No subject was on zidovudine at his first visit. By the time the MRI, P300, and magnetic stimulation studies were done 12 of those in group IV were on zidovudine, and three asymptomatic subjects in group II/III had been randomised in a double-blind placebo controlled Anglo-French prospective trial of zidovudine (Concorde).

At each visit the patients' CDC staging was reviewed. They were examined by a clinical neurologist (RHM) who recorded the results with a specially devised proforma that was transferable to mainframe computer. In addition to the detailed recording of motor, sensory, and cerebellar function, the proforma required the clinician to record at the end of the clinical assessment whether she believed that there was a definite, probable, or possible neurological abnormality (for example, ataxia, peripheral neuropathy, or a cord lesion). The patients then underwent a neuropsychological assessment of approximtely 75 minutes' duration (box) which was administered, scored, and

\section{Neuropsychological test battery}

- Letter cancellation test

Rey auditory verbal learning test

Trail making $A$ and $B$

Non-verbal memory $1^{*}$

Non-verbal memory $2 \star$

Digit symbol substitution *

Facial recognition test

2-Choice reaction time

Wisconsin card sort

Purdue pegboard

Wais block design

Wais picture completion

Wais picture completion

Controlled oral word association test

^Administered using microcomputer

interpreted by a neuropsychologist ( $\mathrm{MH}, \mathrm{PD}$, $\mathrm{SN})$. Formal assessment of depressed mood (Beck depression inventory) and anxiety (Spielberger state and trait) was also carried out. An overall assessment of each subject's mental state was made by administering the clinical interview schedule. On the same day subjects underwent a series of neurophysiological tests (RHM). Nerve conduction tests in the legs included measurement of sural sensory action potential and posterior tibial nerve compound muscle action potentials (MAP) and conduction velocity between knee and ankle (MCV). Minimum F-wave latency from stimulation at the ankle was recorded. Vibration perception threholds were recorded bilaterally from the big toe with a Biothesiometer, with the best of three responses. Somatosensory evoked potentials from the legs to stimulation of both posterior tibial nerves were recorded from a skin electrode over the $\mathrm{L} 1$ spinous process (N20 latency) and a scalp electrode $2 \mathrm{~cm}$ posterior to the vertex (P40 latency). A central latency was then calculated from the difference between these two latencies.

At the second visit the same measures were repeated (not reported here), and in addition long latency event-related potentials (including P300 latency and amplitude) were recorded from $\mathrm{Fz}, \mathrm{Cz}$, and $\mathrm{Pz}$ scalp electrodes (International $10 / 20$ system). These were elicited by a two-tone auditory paradigm in which the subject concentrated on the counted rare high pitched "target" tones randomly distributed among more frequent low pitched tones. One run with $10 \%$ rare (target) tones was followed by a run with $15 \%$ rare tones. Central motor conduction time was also calculated at the second visit. A magnetic coil stimulator (Digitimer Ltd-modified figure of eight stimulator) was used to stimulate the motor cortex (cortical latency) and the lumbosacral roots (root latency). Muscle action potentials were recorded from the flexor hallucis brevis. On a separate occasion but within a month of the other assessments, patients were referred for MRI scanning on an Elscint $0.5 \mathrm{~T}$ superconductive imager. $\mathrm{T} 1$ and $\mathrm{T} 2$ weighted images were generated. Scans were viewed independently by two consultant neuroradiologists (BK and ARV) without access to clinical data or HIV status. If they disagreed the two observers met to discuss the images and tried to reach a consensus. If they still could not agree the scans were scored as equivocal rather than normal or abnormal. Sulcal widening, ventricular enlargement, and focal parenchymatous lesions of abnormal signal characteristics were separately classified.

\section{Results}

At the time of the first assessment 80 patients who were seropositive for HIV-1 were in CDC groups II and III and 15 in group IV. There were 32 in the seronegative comparison group. One patient in group IV had oral candida at the time of the examination; no other subject had evidence of any opportunistic infection. The mean (SD) ages did not differ among the three groups (seronegative 36.6 (7.9) years, seropositive II/III $34.8(6.3)$ years, and seropositive IV $32.5(5.3)$ years). Nor were there any significant differences in social class distribution or educational background. About two thirds came from social classes 1 and 2 , and just over half had been to college or university. Medical histories revealed one patient with cerebral palsy and one with a hereditary spastic paraplegia. Seven described a history of epilepsy, and two had had a severe head injury. A third of the men had suffered psychiatric problems in adult life, usually depression for which 20 had had treatment in the last five years. Anxiety had been medically treated in another nine. Thirty one individuals were on prescribed medication when first seen, and this was more common among seropositive subjects (4/32. (12.5\%) seronegative, subjects $20 / 80$ $(25 \%)$ group II/III; $7 / 15(46 \cdot 7 \%)$ group IV; $\chi^{2}$ $5 \cdot 1, \mathrm{p}<0.05)$. Of the 127 subjects 54 had used cannabis, 21 LSD, and 17 amphetamines or cocaine. Only one subject, who was seronegative, had used intravenous drugs. There was no evidence of any imbalance between the groups. At the time of assessment 11 subjects drank no alcohol, 73 drank up to 20 units per week, 22 drank 21-40 unis, and 21 drank over 
Table 1 Prevalence of neurological abnormalities on clinical examination by CDC status

\begin{tabular}{llcllr}
\hline$C D C$ & Normal & Possible & Probable & Definite & Total (\%) \\
\hline Seronegative & 24 & 5 & 1 & 2 & $8 / 32(25)$ \\
II/III & 53 & 22 & 1 & 2 & $25 / 78(32)$ \\
IV & 9 & 5 & 0 & 1 & $6 / 15(40)$
\end{tabular}

^Two patients with unrelated chronic neurological disability omitted.

Table 2 Psychological performance in HIV infection

\begin{tabular}{|c|c|c|c|c|c|}
\hline \multirow[b]{2}{*}{ Questionnaire } & \multicolumn{3}{|l|}{$C D C$ group } & \multicolumn{2}{|c|}{$A N O V A$} \\
\hline & Seronegative & $I I / I I I$ & $I V$ & $F$ & p Value \\
\hline $\begin{array}{l}\text { Beck } \\
\text { Spielberger (trait) } \\
\text { Spielberger (state) } \\
\text { CIS (reported) } \\
\text { CIS (manifest) }\end{array}$ & $\begin{array}{c}5 \cdot 44 \\
37 \cdot 7 \\
33 \cdot 78 \\
5 \cdot 06 \\
1.25\end{array}$ & $\begin{array}{c}8 \cdot 75 \\
41.9 \\
34.75 \\
5.62 \\
1.99\end{array}$ & $\begin{array}{l}15 \cdot 38 \\
50 \cdot 4 \\
46 \cdot 75 \\
8 \cdot 69 \\
2 \cdot 69\end{array}$ & $\begin{array}{c}12 \cdot 47 \\
8 \cdot 42 \\
13 \cdot 36 \\
76 \cdot 4 \\
3 \cdot 06\end{array}$ & $\begin{array}{l}<0.001 \\
<0.001 \\
<0.0001 \\
<0.02 \\
<0.05\end{array}$ \\
\hline
\end{tabular}

40 units per week. Again there was no difference in alcohol consumption between the seronegative, seropositive and group IV subjects.

At the clinical interview subjects were asked to say if they felt anxious or depressed: $12.5 \%$ $(4 / 32)$ of the seronegative men, $27 \cdot 5 \%(22 / 80)$ seropositive men, and $66 \cdot 7 \%(10 / 15)$ of those with ARC or AIDS said that they felt depressed $(p<0.005)$. None had symptoms directly suggestive of disturbed higher cortical function. Eight patients described parasthesiae and three complained of areas of numbness (there proved to be no correlation between these symptoms and the results of the sensory examination). Few had symptoms suggestive of motor disturbances (seven complained of unsteadiness; four of weakness of the limbs). The two patients with complaints of difficulty in walking had had long standing unrelated neurological conditions (hereditary spastic paraplegia and cerebral palsy). They are omitted from the following account of the results of the neurological examination. Five subjects were felt to have definite abnormalities-for example, lost reflexes or extensor plantar responses, or both-and two a probable abnormality-for example, an ataxic gait. Thirty two more had "possible" change-for example, brisk reflexes unsupported by any other symptom or sign. There was no evidence that such major, minor, or combined abnormalities were any more common in seropositive than seronegative subjects (table $1, \chi^{2} 0 \cdot 77, \mathrm{NS}$ ).

We have presented the results of the psychological and neuropsychological assessments in two ways. In the psychological assessments (table 2) significant differences in depressed

Table 3 Neuropsychological performance in HIV infection. Significant findings (mean scores) at first visit

\begin{tabular}{lllllll}
\hline & \multicolumn{3}{c}{$C D C$ group } & & & \multicolumn{2}{l}{ ANOVA } & \\
\cline { 2 - 3 } \cline { 6 - 7 } Test & Seronegative & II/III & IV & & $F$ & p Value \\
\hline Trailmaking A (secs) & 29.04 & 26.29 & 33.05 & & 4.63 & $<0.02$ \\
Trailmaking B (secs) & 60.39 & 61.72 & 82.48 & & 6.69 & $<0.002$ \\
Digit symbol (secs) & 2.28 & 2.33 & 2.95 & & 10.3 & $<0.0001$ \\
Block design (score) & 14.2 & 13.6 & 11.6 & & 5.8 & $<0.005$ \\
\hline
\end{tabular}

mood (Beck depression inventory), anxiety (Spielberger state and trait), and the clinical interview schedule were found. The findings of both the Beck depression inventory and the Spielberger trait anxiety test indicate that the CDC IV group were more anxious and depressed than the CDC II and III group, who were in turn more anxious and depressed than the seronegative control group. In all the other findings in the psychological assessments the CDC IV group were significantly different from the other groups. On the neuropsychological assessments (table 3 ) the results of four tests were found to be different across CDC status (trailmaking tests $A$ and $B$, digit symbol, and block design). Post hoc tests revealed that for each of these tests the symptomatic seropositive men (CDC IV) performed significantly worse than the two other groups. No differences were found between the asymptomatic men (CDC II and III) and the seronegative men. Furthermore, analysis of covariance indicated that the differences on the neuropsychological tests were not accounted for by differences in mood and psychological state between the groups. In common with other study groups we also considered these findings by examining the percentage of subjects producing performances 2 SD below the mean achieved by the seronegative group on one or more neuropsychological tests. There was a significant difference in the number within each group who met this arbitrary criterion: $7 / 32(22 \%)$ seronegative men $23 / 80$ (29\%) CDC II and III, and 8/15 (53\%) CDC IV $\left(\chi^{2} 6.17, \mathrm{p}<0.05\right)$. Table 4 shows the results of the standard nerve conduction studies. They revealed no differences in group means for sensory or motor conduction, nor were there any differences in vibration perception threshold between seropositive and seronegative groups. Table 5 summarises the lower limb somatosensory evoked potential results. There were no significant differences in the group means between seropositive and seronegative men, whether the individual latencies or the calculated central sensory conduction time were being considered.

Magnetic stimulation was successful from the lumbar region in 68 subjects and from the cortex in 44, making a calculation of central motor conduction time possible in those 44 subjects (table 6). The number in group IV was small ( $\mathrm{n}=$ eight), but there were no significant differences between the means. P300 latencies and amplitudes recorded at $\mathrm{Fz}, \mathrm{Cz}$, and $\mathrm{Pz}$ electrodes to both the $10 \%$ and $15 \%$ rare tones are shown in tables 7 and 8 . Again no significant difference was found between the means according to CDC status, or between seropositive and seronegative men. Ninety seven subjects had technically successful MRI. Twenty five of these were seronegative men, and of the seropositive men, 20 were in group IV by the time of scanning. The two radiologists agreed that 29 sets of images showed one or more abnormalities with 10 showing widened sulci, seven enlarged ventricles, and 13 focal lesions consisting of white matter hyperintensities on T2 weighted scans. There was no evidence that 
Table 4 Nerve conduction tests by CDC group

\begin{tabular}{|c|c|c|c|c|}
\hline Test & Seronegative & $C D C I I / I I I$ & $C D C I V$ & ANOVA \\
\hline $\begin{array}{l}\text { Mean }(\mathrm{SD}) \text { sural SAP }(\mu \mathrm{V}) \\
\text { (Number tested) }\end{array}$ & $\begin{array}{l}10 \cdot 3(6 \cdot 4) \\
(30)\end{array}$ & $\begin{array}{l}9 \cdot 5(4 \cdot 7) \\
(73)\end{array}$ & $\begin{array}{l}10 \cdot 5(5 \cdot 1) \\
(15)\end{array}$ & NS \\
\hline $\begin{array}{l}\text { Mean (SD) sural SCV (m/s) } \\
\text { (Number tested) }\end{array}$ & $42 \cdot 1(5 \cdot 2)$ & $\begin{array}{l}42(5 \cdot 4) \\
(74)\end{array}$ & $42 \cdot 3(4 \cdot 4)$ & NS \\
\hline $\begin{array}{l}\text { Mean (SD) MAP L FHB (mV) } \\
\text { (Number tested) }\end{array}$ & $\begin{array}{l}12 \cdot 5(5 \cdot 6) \\
(32)\end{array}$ & $11 \cdot 7(4 \cdot 6)$ & $\begin{array}{l}13 \cdot 0(5 \cdot 2) \\
(15)\end{array}$ & NS \\
\hline $\begin{array}{l}\text { Mean (SD) MCV Tib N (m/s) } \\
\text { (Number tested) }\end{array}$ & $\begin{array}{l}46 \cdot 6(5 \cdot 5) \\
(32)\end{array}$ & $\begin{array}{l}45 \cdot 5(5) \\
(74)\end{array}$ & $44 \cdot 3(4 \cdot 6)$ & NS \\
\hline $\begin{array}{l}\text { Mean (SD) F Wave Tib N (ms) } \\
\text { (Number tested) }\end{array}$ & $\begin{array}{l}52 \cdot 5(4 \cdot 7) \\
(32)\end{array}$ & $\begin{array}{l}51 \cdot 6(5 \cdot 5) \\
(74)\end{array}$ & $\begin{array}{l}52 \cdot 1(5 \cdot 6) \\
(15)\end{array}$ & NS \\
\hline $\begin{array}{l}\text { Mean (SD) vib thresh right } \\
\text { (Number tested) }\end{array}$ & $\begin{array}{l}9 \cdot 3(8 \cdot 5) \\
(22)\end{array}$ & $\begin{array}{l}7.9(3 \cdot 4) \\
(61)\end{array}$ & $\begin{array}{l}8 \cdot 8(4 \cdot 3) \\
(14)\end{array}$ & NS \\
\hline $\begin{array}{l}\text { Mean (SD) vib thresh left } \\
\text { (Number tested) }\end{array}$ & $\begin{array}{l}7 \cdot 6(4 \cdot 5) \\
(22)\end{array}$ & $\begin{array}{l}7 \cdot 7(3 \cdot 7) \\
(61)\end{array}$ & $\begin{array}{l}7 \cdot 9(2 \cdot 7) \\
(14)\end{array}$ & NS \\
\hline
\end{tabular}

SAP = sensory action potential; SCV = sensory conduction velocity; MAP = muscle action potential; FHB = flexor hallucis brevis; $\mathrm{MCV}=$ motor conduction velocity; $\mathrm{Tib} \mathbf{N}=$ tibial nerve; vib thresh = vibration threshold (biosthesiometer).

Table 5 Lower limb somatosensory potentials. Mean (SD) latencies (ms) by CDC status

\begin{tabular}{lllll}
\hline Latency & Seronegative & CDC II/III & CDC IV & ANOVA \\
\hline Right P40 & $41 \cdot 8(2 \cdot 6)$ & $42(2 \cdot 9)$ & $41 \cdot 7(3 \cdot 5)$ & NS \\
(Number tested) & $(29)$ & $(77)$ & $(15)$ & \\
Left P40 & $41 \cdot 5(2 \cdot 6)$ & $42 \cdot 4(2 \cdot 8)$ & $41 \cdot 7(2 \cdot 9)$ & NS \\
$\quad$ Number tested) & $(30)$ & $(75)$ & $(15)$ & \\
Right N20 & $23 \cdot 8(1 \cdot 6)$ & $24 \cdot 2(1 \cdot 9)$ & $24 \cdot 6(2 \cdot 3)$ & NS \\
(Number tested) & $(27)$ & $(71)$ & $(12)$ & \\
Left N20 & $24 \cdot 0(1 \cdot 7)$ & $24 \cdot 3(2 \cdot 0)$ & $24 \cdot 4(2 \cdot 5)$ & NS \\
(Number tested) & $(29)$ & $(70)$ & $(13)$ & NS \\
Right Central cond time & $17 \cdot 4(1 \cdot 3)$ & $17 \cdot 6(1 \cdot 8)$ & $17 \cdot 1(2 \cdot 1)$ & (11) \\
(Number tested) & $(26)$ & $(71)$ & $(11)$ & NS \\
Left Central cond time & $17 \cdot 4(1 \cdot 4)$ & $18(1 \cdot 6)$ & $17 \cdot 4(2 \cdot 5)$ & (13) \\
$\quad$ (Number tested) & $(29)$ & $(70)$ & $(13)$ & \\
\hline
\end{tabular}

abnormalities were more common in those who were seropositive (table 9). In three of the seropositive men other explanations for imaging abnormalities were present (one with birth injury, one with a severe head injury, and one with a hereditary ataxic paraparesis). When they were excluded the prevalence of abnormality was $25 \%(5 / 20)$ in group IV compared with $15 \%(8 / 52)$ in group II/III, and $52 \%(13 /$ $25)$ in seronegative subjects.

\section{Discussion}

There is good evidence that HIV enters the nervous system at the time of infection and provokes a CSF response that continues during the asymptomatic phase of the illness (CDC II/ III). This suggestion that HIV may be neurotropic like other retroviruses or at least neuroinvasive is supported by the finding of viral specific RNA in the brain at postmortem. ${ }^{1}$ The possibility that early invasion of the nervous system might cause subtle neurological or neuropsychological disturbance is thus entirely reasonable on theoretical grounds, and some early reports claimed to have detected mild to severe cognitive abnormalities in seropositive patients before the

Table 6 Magnetic stimulation of cortex and roots. Mean (SD) latencies (ms) by CDC status

\begin{tabular}{|c|c|c|c|c|}
\hline Latency & Seronegative & $C D C I I / I I I$ & $C D C I V$ & $A N O V A$ \\
\hline $\begin{array}{l}\text { Cortical } \\
\text { (Number tested) }\end{array}$ & $42 \cdot 8(4 \cdot 3)$ & $43 \cdot 4(4 \cdot 7)$ & $42 \cdot 6(5 \cdot 0)$ & NS \\
\hline $\begin{array}{l}\text { Roots } \\
\text { (Number tested) }\end{array}$ & $\begin{array}{l}25 \cdot 5(3 \cdot 1) \\
(23)\end{array}$ & $\begin{array}{l}26 \cdot 3(3 \cdot 9) \\
(32)\end{array}$ & $25 \cdot 0(2 \cdot 6)$ & NS \\
\hline $\begin{array}{l}\text { Central cond } \\
\text { (Number tested) }\end{array}$ & $\begin{array}{l}17 \cdot 2(2 \cdot 6) \\
(16)\end{array}$ & $\begin{array}{l}16.9(2 \cdot 8) \\
(20)\end{array}$ & $\begin{array}{c}17.9(3.7) \\
(8)\end{array}$ & NS \\
\hline
\end{tabular}

development of AIDS. ${ }^{9}$ In that particularly influential paper Grant et al examined four groups including sixteen seropositive subjects without either ARC or AIDS and 11 seronegative male homosexuals on a battery of eight tests. ${ }^{9}$ Each subject was scored on each test as normal or probably, or definitely impaired, and if one test result was definitely impaired or two were probably impaired that individual was classified as being abnormal. Seven of 16 seropositive subjects were so classified compared with one of the 11 controls, supporting the notion that neuropsychological deterioration was apparent in individuals with HIV who were otherwise asymptomatic. In 1988 Tross et al reported a cross-sectional study of 20 seronegative subjects, 16 seropositive subjects and 44 newly diagnosed AIDS patients with a battery of neuropsychological tests. ${ }^{12}$ All patients were apparently checked for alcohol or intravenous drug abuse, though formal questionnaires about substance abuse were not administered. Each test was assigned a criterion for impaired performance which was based on published norms. More individuals were assessed as performing abnormally on one or more tests in the AIDS group and in the seropositive subjects when compared with seronegative subjects, though the numbers were small. Another small series ${ }^{13}$ found nine of 18 seropositive subjects and two of 26 seronegative subjects abnormal in a blind rating of a neuropsychological test battery. In all these studies the sample sizes were small and no attempt was made to examine whether mood accounted for the differences observed.

Several larger prospective studies, including our own, were triggered. The MACS investigation recently reported on the cross sectional prevalence of neurological abnormalities in $\mathbf{2 7 0}$ HIV-1 seropositive men in CDC II/III and 193 HIV-1 seronegative homosexual men. ${ }^{14}$ No significant differences were detected on a screening assessment or in the subset of 119 subjected to a more detailed clinical and neuropsychological examination. Thus 29 of 193 seronegative subjects $(15 \%)$ and 31 of $218(14 \%)$ seropositive subjects appeared abnormal on the neuropsychological screening battery of five tests and nine of $39(23 \%)$ seronegative and 15 of $68(22 \%)$ seropositive subjects on a second neuropsychological test battery, administered to those with one or more abnormalities on the screening battery (as defined by a score 1.5 SD below norms on two or more tests or $2.5 \mathrm{SD}$ below on one). The neurological assessments recorded abnormalities (commonly on sensory examination or of reflexes) in 10 of 44 seronegative $(23 \%)$ and 24 of $75(32 \%)$ seropositive subjects. Only one HIV-1 positive subject had evidence of dementia (combined with signs of a peripheral neuropathy). A similar study from San Francisco $^{15}$ enrolled 100 seropositive subjects (26 with ARC) who were compared with 157 seronegative subjects, all homosexual or bisexual males. There were no significant differences in the potentially confounding variables such as age, educational background, and drug and alcohol use. Patients with ARC, but not 
Table 7 Event related P300 evoked potential. Mean latencies (ms) by CDC status

\begin{tabular}{|c|c|c|c|c|c|}
\hline Paradigm & Electrode & Seronegative & $C D C I I / I I I$ & $C D C I V$ & ANOVA \\
\hline $\begin{array}{l}10 \% \text { Tones } \\
\text { (Number tested) } \\
10 \% \text { Tones } \\
\text { (Number tested) } \\
10 \% \text { Tones } \\
\text { (Number tested) } \\
15 \% \text { Tones } \\
\text { (Number tested) } \\
15 \% \text { Tones } \\
\text { (Number tested) } \\
15 \% \text { Tones } \\
\text { (Number tested) }\end{array}$ & $\begin{array}{l}\text { Frontal } \\
\text { Central } \\
\text { Parietal } \\
\text { Frontal } \\
\text { Central } \\
\text { Parietal }\end{array}$ & $\begin{array}{l}308 \cdot 9 \\
(21) \\
310 \cdot 5 \\
(21) \\
317 \cdot 4 \\
(21) \\
329 \cdot 2 \\
(17) \\
332 \cdot 1 \\
(16) \\
339 \cdot 0 \\
(17)\end{array}$ & $\begin{array}{l}321 \cdot 6 \\
(29) \\
319 \cdot 2 \\
(30) \\
328 \cdot 6 \\
(28) \\
322 \cdot 2 \\
(26) \\
326 \\
(29) \\
333 \cdot 9 \\
(29)\end{array}$ & $\begin{array}{l}316 \\
(15) \\
316 \cdot 3 \\
(14) \\
330 \cdot 4 \\
(14) \\
323 \cdot 5 \\
(13) \\
328 \cdot 3 \\
(12) \\
340 \cdot 5 \\
(8)\end{array}$ & $\begin{array}{l}\text { NS } \\
\text { NS } \\
\text { NS }\end{array}$ \\
\hline
\end{tabular}

Table 8 Event related P300 evoked potentials. Mean amplitude $(\mu \mathrm{V})$ by CDC status

\begin{tabular}{|c|c|c|c|c|c|}
\hline Paradigm & Electrode & Seronegative & $C D C I I / I I I$ & $C D C I V$ & $A N O V A$ \\
\hline $\begin{array}{l}10 \% \text { Tones } \\
\text { (Number tested) } \\
10 \% \text { Tones } \\
\text { (Number tested) } \\
10 \% \text { Tones } \\
\text { (Number tested) } \\
15 \% \text { Tones } \\
\text { (Number tested) } \\
15 \% \text { Tones } \\
\text { (Number tested) } \\
15 \% \text { Tones } \\
\text { (Number tested) }\end{array}$ & $\begin{array}{l}\text { Frontal } \\
\text { Central } \\
\text { Parietal } \\
\text { Frontal } \\
\text { Central } \\
\text { Parietal }\end{array}$ & $\begin{array}{l}10 \cdot 1 \\
(21) \\
12 \cdot 7 \\
(21) \\
13 \cdot 2 \\
(21) \\
7 \cdot 9 \\
(17) \\
9 \cdot 0 \\
(16) \\
9 \cdot 6 \\
(17)\end{array}$ & $\begin{array}{l}9 \cdot 9 \\
(29) \\
11 \cdot 7 \\
(30) \\
12 \cdot 3 \\
(28) \\
8 \cdot 3 \\
(26) \\
10 \cdot 5 \\
(29) \\
10 \cdot 1 \\
(29)\end{array}$ & $\begin{array}{r}8 \cdot 6 \\
(15) \\
11 \cdot 2 \\
(14) \\
11 \cdot 3 \\
(14) \\
6 \cdot 5 \\
(13) \\
9 \cdot 6 \\
(12) \\
10 \cdot 2 \\
(8)\end{array}$ & $\begin{array}{l}\text { NS } \\
\text { NS } \\
\text { NS } \\
\text { NS }\end{array}$ \\
\hline
\end{tabular}

those in groups II/III, performed worse on tests of memory and perceptual speed (digit symbol) in a short test battery. Scores on the state anxiety inventory were higher in seropositive subjects especially those with ARC but these did not explain the difference in performance of the neuropsychological tests in a regression model. Eighty five of the subjects volunteered for a fuller neuropsychological test battery. Again only subjects with ARC were more likely to score abnormally than HIV-1 seronegative subjects. Thus abnormal results were noted in seven of $16(44 \%)$ with ARC, four of $28(14 \%)$ seropositive subjects, and five of $41(12 \%)$ seronegative subjects. Eighty three asymptomatic subjects from 649 US Air Force personnel with HIV-1 antibodies were tested with a six test battery and compared with 18 seronegative men in basic military training being tested many years after minor head injury. ${ }^{16}$ No significant differences were detected. A small group with immunological and CSF abnormalities performed less well on a verbal memory task.

Our own data agree with those of the larger series but not with those involving less than 70 subjects. No significant differences in neuropsychological performance were detected between asymptomatic seropositive and seronegative subjects but those in group IV performed less well. Several tests showed lower mean scores in group IV. Differences in mood and anxiety had some effect but part of the difference between group IV and others was not

Table 9 Prevalence of abnormality on magnetic resonance imaging by CDC status

\begin{tabular}{lllll}
\hline MRI result & Seronegative & CDC II/III & CDC IV & Total \\
\hline Normal & 12 & 40 & 13 & 65 \\
Abnormal & $13(52 \%)$ & $11(22 \%)$ & $5(25 \%)$ & $29(30 \%)$ \\
Equivocal & 0 & 1 & 2 & 3 \\
Total & 25 & 52 & 20 & 97 \\
\hline
\end{tabular}

explicable by their influence. The differences between the studies with small and large numbers of subjects highlights the need for adequate numbers, careful matching of educational level and age, and concurrent assessments of mood and anxiety. Seronegative subjects from similar backgrounds are a crucial comparison group. The larger studies, including our own, which had a comparison group well-matched for age, education, and alcohol and drug use, and which took mood into account showed no evidence of a subclinical cognitive impairment in CDC groups II/III. An analysis of the $95 \%$ confidence intervals associated with all the studies reviewed above indicated that in only one of the small sample studies $^{13}$ did the asymptomatic and seronegative groups differ significantly. Patients with group IV disease do tend to show evidence of some impairment in most studies.

Selection of neuropsychological tests is also an important issue. A recent study compared 46 HIV seropositive subjects with 13 seronegative subjects. ${ }^{17}$ The seropositive subjects were in CDC groups II or III but had CD4 counts under 700. Deviations of 2 SD from the mean score of the control group were recorded on four or more tests in $22 \%$ of the seropositive subjects and none of the seronegative subjects. The difference in this study was the inclusion of more complex tasks. Traditional tests did not discriminate between the groups. Obviously a larger comparison group will be neded before it can be suggested that high level impairment is being missed in all the other studies. MRI has proved very successful in diagnosing opportunistic infections in AIDS patients. In asymptomatic subjects sulcal dilatation, ventricular enlargement, and focal areas of abnormal signal from the white matter which might have been expected to be markers of any subclinical encephalitis have proved, in the present study and in the MACS study, ${ }^{18}$ to be no more common in seropositive than seronegative groups. In the latter study, $24 \%$ of the HIV-1 seronegative subjects, $26 \%$ of asymptomatic seropositive subjects (II/III), and $17 \%$ of those with ARC/AIDS had focal hyperintensities in the white matter. There was no correlation between such abnormalities and neurological findings, drug history, or neuropsychological results. Our own data are concordant with additional evidence that signs of atrophy were also no more common in those in CDC II/III or IV. We plan to investigate the possibility that quantitative changes in magnetic signal from apparently normal white matter may be more revealing.

A wide variety of peripheral neuropathies is recognised in HIV infected individuals. ${ }^{7}$ A painful axonal sensory neuropathy in group IV disease is the commonest, but there have also been occasional reports of mild conduction abnormalities in individuals in groups II and III. ${ }^{1920}$ Some studies have screened asymptomatic seropositive subjects and reported abnormalities interpreted as indicative of a subclinical neuropathy. These studies, however, have tended to lack a seronegative comparison group or failed to show due atten- 
tion to the confounding effects of alcohol etc. The use of published norms or of historical controls is inappropriate in this context. Our results of investigating nerve conduction in the legs revealed no evidence of any abnormality in group II/III subjects when compared with seronegative controls. The analysis of the follow up study will help to clarify whether there is any trend towards a declining motor and sensory conduction velocity in HIV seropositive patients as suggested by Jakobsen. ${ }^{20}$ Evoked potential studies have been widely used to try to detect spinal or cerebral involvement with HIV-1. For example Smith et al ${ }^{1}$ reported prolonged latencies at T12 when stimulating the posterior tibial nerve. They inferred a conduction defect at the level of dorsal root ganglia or the lumbar roots or cord. The same group also reported prolonged brain stem evoked responses, and Goodin et al demonstrated abnormalities of event related P300 evoked potentials, which have been held to support the idea of subclinical cerebral impairment. ${ }^{22}$ Neither group of workers included a matched seronegative comparison group and the specificity or their findings is thus unknown. Our own data cast doubt on the relevance of such reports as we found no evidence that seropositive subjects had abnormalities of somatosensory of $\mathrm{P} 300$ responses when compared under tightly controlled conditions with seronegatives.

Our cross sectional study and the review of the results of other large controlled studies thus show no evidence of widespread subclinical involvement of either the peripheral or central nervous systems in subjects in CDC stages II and III. In stage IV there is evidence of emerging abnormality. The review of published data highlights the need for an appropriate seronegative comparison group and further study of the MRI changes in the seronegative group to understand better the pathogenesis of subtle findings in individuals subjected to such detailed testing. The conclusion that there is no sign of early subclinical neurological abnormality is of practical importance in the planning and provision of routine care and the monitoring of drug trials and is of theoretical interest. It implies that, despite early invasion of the CNS by HIV, major disturbances of function manifest themselves only when the patient becomes significantly immunosuppressed.

We are grateful to our colleagues and the volunteers for their enthusiastic and patient help with this study. Particular thanks are due to Professor S Semple, J Quirk (supported by the Frances and Augustus Newman Foundation), M Beecham M Boland, G Griffin, C Kirkis, C Morgan, and the staff of the MRI Centre, London. The study was supported throughout by a grant from the Medical Research Council.

1 Ho DD, Rota TR, Schooley RT, et al. Isolation of HTLVIII from cerebrospinal fluid and neural tisues of patients with neurologic syndromes related to the acquired immunodeficiency syndrome. N Eng J Med 1985;313 1493-7.

2 Hollander H, Levy JA. Neurologic abnormalities and recovery of human immunodeficiency virus from cerebrospinal fluid. Ann Int Med 1987;106:692-5.

3 McArthur JC. Neurologic manifestations of AIDS Medicine 1987;66:407-37.

4 Perry S, Marotta R. AIDS dementia: a review of the literature. Alzheimer Dis Assoc Disord 1987;1:221-35.

5 Navia BA, Cho E-S, Petito CK, et al. The AIDS dementia complex: II neuropathology. Ann Neurol 1986;19:525-35.

6 Johnson RT, McArthur JC, Narayan O. The neurobiology of human immunodeficiency virus infection. FASEB J of human immi

7 Leger JM, Bouche P, Bolgert F, et al. The spectrum of polyneuropathies in patients infected with HIV. J Neurol Neurosurg Psychiatry 1989;52:1369-74.

8 Petito CK, Navia BA, Cho E-S, et al. Vacuolar myelopathy pathologically resembling subacute combined degeneration in patients with the acquired immunodeficiency syndrome. N Engl J Med 1985;312:874-9.

9 Grant I, Atkinson JH, Hesselink JR, et al. Evidence for early central nervous system involvement in the acquired immunodeficiency syndrome (AIDS) and other immunodeficiency virus (HIV) infections. Ann Int Med 1987;107:828-36.

10 Centers for Disease Control. Classification system for human T-lymphotropic virus type III/Lymphadenopathy-associated virus infections. Ann Intern Med 1986;35:334-9.

11 Kelly GE, Stanley BS, Weller IVD. The natural history of human immunodeficiency virus infection: a five year study in a London cohort of homosexual men. Genitourin Med 1991 , in press.

12 Tross S, Price RW, Navia B, et al. Neuropsychological characterisation of the AIDS dementia complex: a preliminary report. AIDS 1988;2:81-8.

13 Saykin AJ, Janssen RS, Sprehn G, et al. Neuropsychological dysfunction in HIV-infection: characterisation in a lymphadenopathy cohort. Int J Clin Neuropsychol 1988;10: 81-93.

14 McArthur JC, Cohen BA, Selves OA, et al. Low prevalence of neurological and neuropsychological abnormalities in otherwise healthy HIV-1-infected individuals: results from the multicenter AIDS cohort study. Ann Neurol 1989;26:601-11.

15 Janssen RS, Saykin AJ, Cannon L, et al. Neurological and neuropsychological manifestations of HIV-1 infection: association with AIDS-related complex but not asymp
tomatic HIV-1 infection. Ann Neurol 1989;26:592-600.

16 Goethe KE, Mitchell JE, Marshall DW, et al. Neuropsychological and neurological function of human immunodeficiency virus seropositive asymptomatic individuals. deficiency virus seropositive
Arch Neurol 1989;46:129-33.

17 Wilkie FL, Eisdorfer C, Morgan R, et al. Cognition in early human immunodeficiency virus infection. Arch Neurol 1990;47:433-40.

18 McArthur JC, Kumar AJ, Johnson DW, et al. Incidental white matter hyperintensities on magnetic resonance maging in HIV-1 infection. J Acq Imm Def Syn 1990; 3:252-9.

19 Carne CA, Stibe C, Bronkhurst A, et al. Subclinical neurological and neuropsychological effect of infection with HIV. Geniturin Med 1989;65:151-6.

20 Jakobsen J, Smith T, Gaub J, et al. Progressive neurological dysfunction during latent $\mathrm{HIV}$ infection. $B M J$ 1989; 299:225-8.

21 Smith T, Jakobsen J, Gaub J, et al. Clinical and electrophysiological studies of human immunodeficiency virus physiological studies of human immunodeficiency virus
seropositive men without AIDS. Ann Neurol 1988;23: 295-7.

22 Goodin DS, Aminoff MJ, Chernoff D, et al. Long latency event-related potentials in patients infected with human immunodeficiency virus. Ann Neurol 1990;27:414-9. 